\title{
Genotyping and Phylogenetic Analysis of Cystic Echinococcosis Isolated from Camels and Humans in Egypt
}

\author{
Nashwa O Khalifa ${ }^{1}$, Hanem F. Khater ${ }^{2, *}$, Hanan A. Fahmy ${ }^{3}$, Mervat E.I.Radwan ${ }^{4}$, Jehan S.A. Afify ${ }^{5}$ \\ ${ }^{1}$ Zoonoses Department, Faculty of Veterinary Medicine, Benha University, Toukh, Egypt \\ ${ }^{2}$ Parasitology Department, Faculty of Veterinary Medicine, Benha University, Toukh, Egypt \\ ${ }^{3}$ Biotechnology Department, Animal Health Research Institute (AHRI), Giza, Egypt \\ ${ }^{4}$ Department of infectious Diseases, Faculty of Veterinary Medicine, Benha University, Toukh, Egypt \\ ${ }^{5}$ Department of Food Hygiene, Faculty of Veterinary Medicine, Benha University, Toukh, Egypt \\ *Corresponding author: dr_mervat19@yahoo.com
}

Received March 07, 2014; Revised May 04, 2014; Accepted May 13, 2014

\begin{abstract}
The objectives of the present study were to investigate strain identification of Echinococcus granulosus infecting camel and human in Qalyubia, Egypt. Therefore partial sequences were generated after gel purification of nested PCR amplified products of mitochondrial NADH 1gene of Echinococcus granulosus complex. Sequences were further examined by sequence analysis and subsequent phylogeny to compare these sequences to those from known strains of E.granulosus circulating globally and retrieved from GenBank. All isolates are homologous to the camel strain, E. canadensis (G6) genotype. Nucleotide mutations generate polymorphism at position of 275 nucleotide, where a thymine replaced a cytosine and at the levels of 385 and 386 nucleotides, where two cytosine substituted a guanine and a thymine respectively. KF815488 Egypt showed typical identity (99.5\%) with JN637176 Sudan, HM853659 Iran, AF386533 France and AJ237637 Poland with 0.5\% diversion.. Phylogenetic analysis showed a robust tree clustering all isolates with sequences belonging to the camel genotype (G6) variant with strong bootstrap values at relevant nodes and the evolutionary distance between groups is very short. There are two mutations in the sequences of amino acids at the position of 92, where an Alanine is changed to a Valine and at the position of 129, where a Valine is transformed to a Proline. Our record of a single genotype determined a strain which could be incriminated for camel and human infectivity and responsible for its persistence in the endemic areas. Such epidemiological data could guide the application of efficient control strategies of hydatidosis in Egypt.
\end{abstract}

Keywords: Echinococcus granulosus, sequences, phylogeny, nucleotide, mutation

Cite This Article: Nashwa O Khalifa, Hanem F. Khater, Hanan A. Fahmy, Mervat E.I.Radwan, and Jehan S.A. Afify, "Genotyping and Phylogenetic Analysis of Cystic Echinococcosis Isolated from Camels and Humans in Egypt." American Journal of Epidemiology and Infectious Disease, vol. 2, no. 3 (2014): 74-82. doi: 10.12691/ajeid-2-3-2.

\section{Introduction}

Cystic echinococcosis (CE) is an important zoonotic disease affecting various species of livestock and humans, caused by metacestodes of dog tapeworms of the Echinococcus granulosus complex (Eg complex). The adult worm lives in the small intestine of a carnivore (definitive host), while the larval stage develops in the internal organs of an intermediate host, mainly in the lung and liver $[1,2,3]$ which acquires the infection through accidental ingestion of the tapeworm eggs. Hydatid cyst develops in the internal organs of human and herbivore intermediate hosts. CE represents an increasing public health and socio-economic concern in Egypt [4] and many areas of the world especially in many rural, grazing areas of Africa [1,5]. Asia (, and [6,9] Australia [10].
Hydatid infection often leads to a decline of health status that in turn translates into serious production losses to humans and livestock industries. Economic losses arise not only from the condemnation of infected viscera, but also from reduction in yield and quality of meat, milk, wool, hide value, birth rate, and fecundity [11] Humans are accidentally infected by ingestion of food or drinking of water contaminated with dog feces containing infective eggs [12] CE is considered an emerging and re-emerging disease in many parts of the world [13]. The global burden of CE is estimated at $>1,000,000$ DALYs (disability adjusted life years) lost, which gives $\mathrm{CE}$ a greater impact than onchocercosis, Dengue fever and Chagas disease, and approaches the burden caused by African trypanosomosis and schistosomosis [14] Human hydatidosis is typically a symptomatic because of the slow growth of metacestodes. Clinical symptoms usually do not become evident until 10 years or more after initial infection [15] (Sako et al. 2011). 
Early diagnosis and treatment are important for reduction of morbidity and mortality[16] (Sarkari et al. 2007).

The disease is usually diagnosed in patients using imaging technique as ultrasonography [17] (Sako et al. 2002). Camels seemed to play an important role in the transmission cycle of the parasite and the epidemiology of the disease especially in rural communities, where dogs infected by eating infected camel carcasses containing the hydatid cysts[18].

Studies based on mitochondrial DNA analysis have demonstrated that E. granulosus is actually a complex of species/genotypes which exhibit a marked genetic variability. Therefore, at least ten distinct genotypes (G1G10) have been identified within the E. granulosus complex[19]. These include two sheep strains (G1 and G2), two bovid strains (G3 and G5), a horse strain (G4), a camel strain (G6), two pig strains (G7 and G9), and two cervid strains (G8 and G10). In addition, recent molecular evidence suggests that infections in wild carnivores are likely caused by a specific strain (G11) named E. felidis. This genotype has been documented in lions and hyenas[20] (Huttner et al. 2008). Genotypes G1-G3 cluster firmly together to form the taxon, E. granulosus sensu stricto (E. granulosus s.s.). These variants have broad geographical distributions and a wide range of host specificity and are responsible (particularly G1) for most human infections. The more distantly related genotype cluster G6-G10 (E. canadensis) includes strains that are all infective to humans, but to a much lesser extent than those from E. granulosus s.s. [19].

Studying the genetic characterization of the population structure of E. granulosus [21] has significant implications fo epidemiological and control studies. However, only one study has explored the population structure of E. granulosus from Cairo, Egypt [22]. Therefore, the objectives of the present study were to investigate profoundly the molecular characterization of E. granulosus isolates from camels and humans by sequence and phylogenetic analyses of a fragment of the mitochondrial NADH dehydrogenase 1 gene as well as the nucleotide and protein polymorphism in the circulating genetic variants in Qalyubia Governorate, Egypt, and to compare our findings to those related to known strains of E. granulosus circulating globally. Consequently, this study is regarded as the first attempt in Qalyubia Governorate, to the best of our knowledge, for determination of a strain which could be incriminated for camel and human infectivity.

\section{Materials and Methods}

\subsection{E. granulosus Isolates}

For continuation of our previous work, under publication, twenty- five fertile cyst fluids recovered form lungs and livers were used as follows. Twenty isolates were recovered form of camels slaughtered at the official slaughterhouses of Toukh and Benha (35 and $50 \mathrm{~km}$ apart north Cairo, respectively), Qalyubia Governorate, Egypt, during the period from October 2012 to September 2013. Five hydatid- cyst fluids were recovered, according to [12] from humans (45-55 years old) admitted to Toukh's hospital and Benha insurance hospital, Qalyubia Governorate, Egypt, during the last two years. Samples of protoscolices isolated form cysts were used for genetic characterization and stored at $-20{ }^{\circ} \mathrm{C}$ until used according to [23] Samples were subjected to nested PCR using two pairs of oligonucleotide primers of mitochondrial NADH dehydrogenase 1 gene primers, the first amplification step was conducted through using the outer primer EGL1 and EGR2 and the second amplification step analyzed by using the inner primer EGL3 and EGR4, as a result, the expected fragments 435 bp and 276 bp were identified respectively.

\subsection{Sequence Analysis}

The PCR products were gel purified by using QIAquick gel extraction kit (Qiagen, Valencia, Calif.) following the manufacture's instruction The purified PCR product was sequenced by using BigDye Terminator v3.1 Cycle Sequencing Kit on an automatic sequencer (3500 Genetic Analyzer; Applied Biosystems, Foster City, CA). The nucleotide sequences were then algined with existing sequences of known genotypes from other countries in the GenBank databases using BLAST programs and databases of the NCBI (National Center for Biotechnology Information, Bethesda, MD, USA) (www.blast.ncbi.nlm.nih.gov/Blast.cgi).

\subsection{Phylogenetic Analysis}

Phylogenetic analyses were based on alignments obtained from ClustalW method using Bioedit (DNA analysis program) of a partial sequence of $276 \mathrm{bp}$ length of NADH dehydrogenase 1 gene of the Egyptian camel G6 strain was carried out using MEGA software v5.0 as cited by [24]. The Phylogenetic tree were constructed using the neighbour-joining of MegAlign program from LaserGene Biocomputing Software Package (DNASTAR, Madison, WI).

\section{Results}

Partial sequencing of the NADH dehydrogenase 1 gene produces a sequence of 399 bp for each sample and submitted to the GenBank database with the accession (KF 815488). Camel and human isolates are homologous to the camel strain (G6) E. Canadensis.

Sequence alignment was compared with previously reported nineteen references of E. granulosus G6 genotypes of the most similar sequences retrieved from GenBank to identify the genotype of the isolate (Figure 1). Nucleotide sequencing revealed the occurrence of nucleotide mutations generating a single nucleotide polymorphism at position of 275 nucleotide, where a thymine $(\mathrm{T})$ replaced a cytosine (C) and at the levels of 385 and 386 nucleotides, where two cytosine (CC) substituted a guanine and thymine (G T) respectively (Figure 1 ).

The analysis of genetic diversity based on partial mitochondrial DNA sequencing represented the percent of diversion and identity between the new Egyptian isolate and nineteen selected sequences E.granulosus G6 circulating globally and retrieved from GenBank displayed in Table 1, it revealed that our isolate showed typical identity (99.5\%) with JN637176 Sudan, HM853659 Iran, AF386533 France and AJ237637 Poland with $0.5 \%$ diversion while the percentage of identity reached its lowest degree 96.4\% with HQ423292 Canada. 


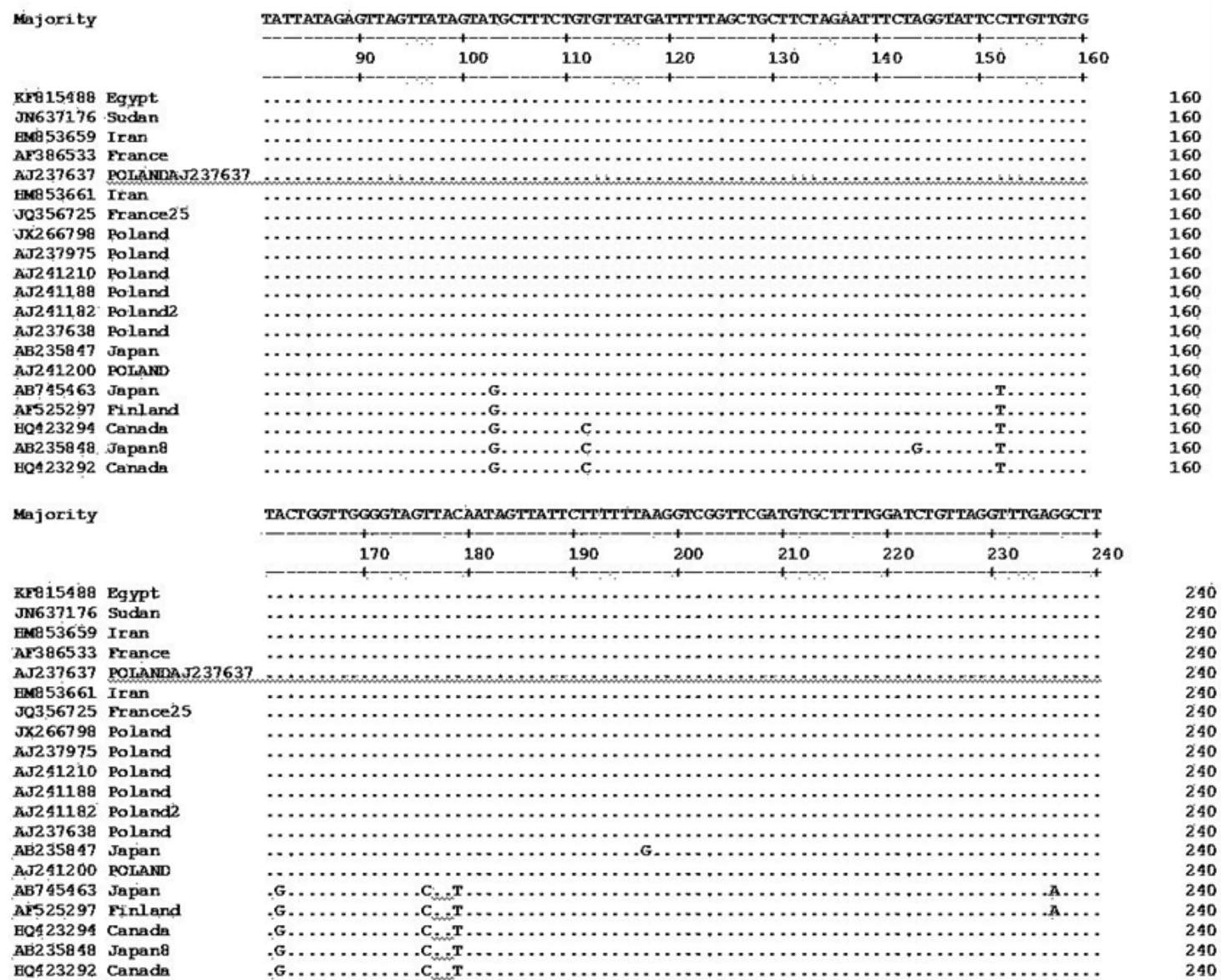

Majority

GTTTTATGTGTGTGGTATTTTTTGCGTTTATGCTGTTGTGGGTATAATTTAATTGATTTTTATTATAGTTACTGGTGA

\begin{tabular}{|c|c|}
\hline KFP15488 & $Y$ \\
\hline JN637176 & Sudan \\
\hline HM8 53659 & Iran \\
\hline AF386533 & France \\
\hline AJ237637 & POLAREA 237637 \\
\hline HMP 53661 & Iran \\
\hline 30356725 & France25 \\
\hline $\mathrm{J} \times 266798$ & Poland \\
\hline Aง237975 & Poland \\
\hline AJ241210 & Poland \\
\hline A 241188 & Poland \\
\hline AJ241182 & Poland2 \\
\hline AN237638 & Poland \\
\hline AB235847 & Japan \\
\hline AJ241200 & POLARE \\
\hline AB745463 & Japan \\
\hline AF525297 & Finland \\
\hline HQ4 23294 & Canada \\
\hline AB235848 & Japan8 \\
\hline FO4 23292 & Canada \\
\hline
\end{tabular}

\begin{tabular}{|c|c|c|c|c|c|c|}
\hline 250 & 260 & 270 & 280 & 290 & 300 & 310 \\
\hline
\end{tabular}

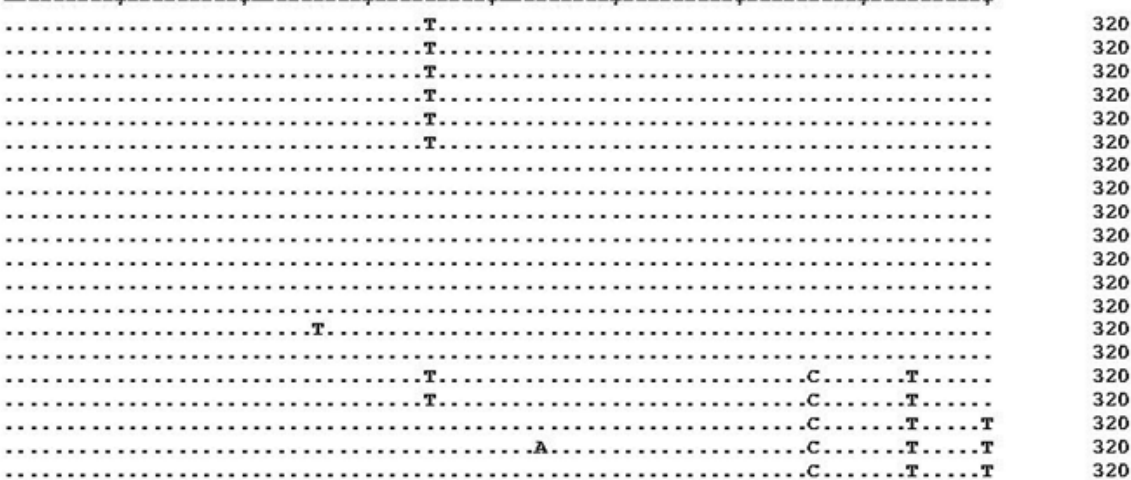

Majority

AGTTGATTATTATTCCCATTAATTTATGGGTATTCTTGGTGTGTGTGTTGTGTGAGACTAATCGTACTCCATTTGATT

\begin{tabular}{|c|c|}
\hline & \\
\hline N637176 & Sudan \\
\hline HMA 53659 & Iran \\
\hline & \\
\hline A.J237637 & POLANEA 237637 \\
\hline FMQ 53661 & Iran \\
\hline J0356725 & France25 \\
\hline JX266798 & Poland \\
\hline AN237975 & Poland \\
\hline AJ 241210 & Poland \\
\hline AN24118a & Poland \\
\hline AJ241182 & Poland2 \\
\hline AN237638 & Poland \\
\hline AB235847 & Japan \\
\hline AJ 241200 & POLAND \\
\hline AB745463 & Japan \\
\hline AF525297 & Finland \\
\hline EO423294 & Canada \\
\hline AB23584a & Japan \\
\hline EO423292 & Canada \\
\hline
\end{tabular}

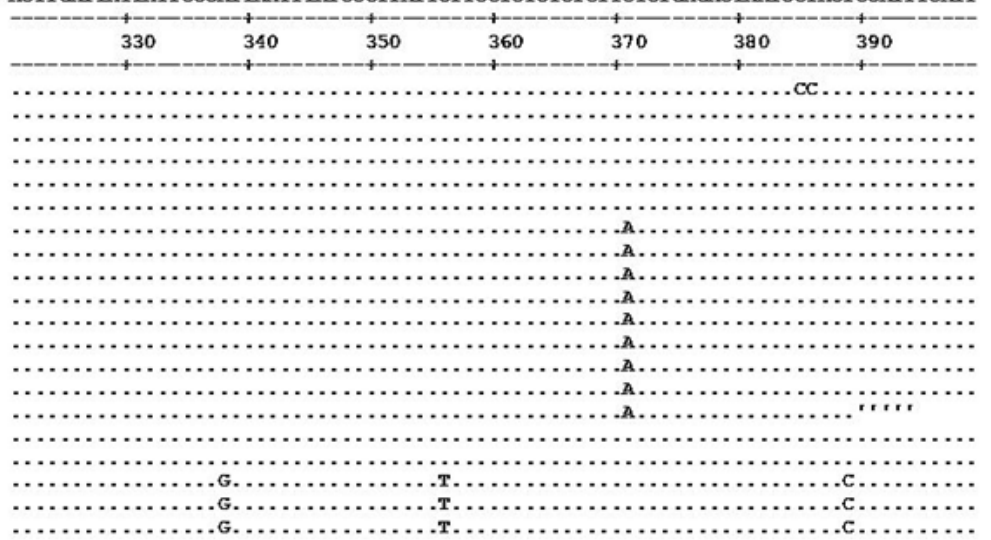

Figure 1. Nucleotide sequence alignment of NADH dehydrogenase 1 gene. Reference sequences for the NADH dehydrogenase 1 gene for the genotype G6 variant are shown with a random selection of isolate sequences beneath showing identity with the camel strain G6 genotype.Three nucleotides mutation in KF815488 Egypt at positions 275,385 and 386 
Table 1. The percent of diversion and identity between the new isolate sample from Egypt and nineteen selected sequences circulating globally from GenBank

\begin{tabular}{|c|c|c|c|c|c|c|c|c|c|c|c|c|c|c|c|c|c|c|c|c|c|c|}
\hline \multicolumn{23}{|c|}{ Percent Identity } \\
\hline & 1 & 2 & 3 & 4 & 5 & 6 & 7 & 8 & 9 & 10 & 11 & 12 & 13 & 14 & 15 & 16 & 27 & 18 & 19 & 20 & & \\
\hline 1 & & 99.5 & 99.5 & 99.5 & 99.5 & 99.2 & 99.0 & 99.0 & 99.0 & 99.0 & 99.0 & 99.0 & \begin{tabular}{|l|}
99.0 \\
\end{tabular} & 98.5 & 97.7 & 97.2 & 97.2 & 96.2 & \begin{tabular}{|l|}
95.7 \\
\end{tabular} & 95.5 & 1 & $\mathrm{KF}$ \\
\hline 2 & 5 & & 0 & 100.0 & 100.0 & 99.7 & 99.5 & 9.5 & 99.5 & 99.5 & 99.5 & 99.5 & \begin{tabular}{|l|}
99.5 \\
\end{tabular} & 99.5 & 98.7 & 97.2 & 97.2 & 96.7 & 96.2 & 96.0 & 2 & 176 \\
\hline 3 & 0.5 & 0.0 & & 100.0 & 100.0 & 99.7 & 99.5 & 99.5 & 99.5 & 99.5 & 99.5 & 99.5 & 99.5 & 99.5 & 98.7 & 97.2 & 97.2 & 96.7 & 96.2 & 96.0 & 3 & 353659 \\
\hline 4 & & 0.0 & 0.0 & & 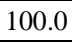 & 99.7 & 99.5 & 9.5 & 5 & 99.5 & 99.5 & 99.5 & 99.5 & 99.5 & 98.7 & 97.2 & 97.2 & 96.7 & 96.2 & 96.1 & 4 & 533 \\
\hline 5 & 0.5 & 0.0 & 0.0 & 0.0 & & 99.7 & 99.5 & 99.5 & 99.5 & 99.5 & 99.5 & 99.5 & 99.5 & 99.5 & 98.7 & 97.2 & 97.2 & 96.7 & 96.2 & 96.0 & 5 & 7637 \\
\hline 6 & 0 & 0.3 & 0 . & 0.3 & 0.3 & & 99.2 & 99.2 & 99.2 & 99.2 & 99.2 & 99.2 & 99.2 & 98.7 & 98.0 & 97.5 & 97.5 & 96.5 & 96.0 & 95 & 6 & 561 \\
\hline 7 & 1.0 & 0.5 & 0.5 & 0.5 & 0.5 & 0.8 & & 100.0 & 100.0 & 100.0 & 100.0 & 100.0 & 100.0 & 99.5 & 98.7 & 97.2 & 97.2 & 96.7 & 96.2 & 96.0 & 7 & 6723 \\
\hline 8 & 1.0 & 0.5 & 0.5 & 0.5 & 0.5 & 0.8 & 0.0 & & 100. & 100.0 & 100.0 & 100.0 & 100.0 & 99.5 & 98.7 & 97.2 & 97.2 & 96.7 & 96.2 & 96. & 8 & 798 \\
\hline 9 & 1.0 & 0.5 & 0.5 & 0.5 & 0.5 & 0.8 & 0.0 & 0.0 & & 100.0 & 100.0 & 100.0 & 100.0 & 99.5 & 98.7 & 97.2 & 97.2 & 96.7 & 96.2 & 96.0 & 9 & AJ237975 \\
\hline 10 & 1.0 & 0.5 & 0.5 & 0.5 & 0.5 & 0.8 & 0.0 & 0.0 & 0.0 & & 100.0 & 100.0 & 100.0 & 99.5 & 98.7 & 97.2 & 97.2 & 96.7 & 96.2 & 96.0 & 10 & 210 \\
\hline 11 & 1.0 & 0.5 & 0.5 & 0.5 & 0.5 & 0.8 & 0.0 & 0.0 & 0.0 & 0.0 & & 100.0 & 100.0 & 99.5 & 98.7 & 97.2 & 97.2 & 96.7 & \begin{tabular}{|l|}
96.2 \\
\end{tabular} & 96.0 & 11 & 188 \\
\hline 12 & 1.0 & 0.5 & 0.5 & 0.5 & 0.5 & 0.8 & 0.0 & 0.0 & 0. & 0.0 & 0.0 & & 100.0 & 99.5 & 98.7 & 97.2 & 97.2 & 96.7 & 96.2 & 96.0 & 12 & 182 \\
\hline 13 & 1.0 & 0.5 & 0.5 & 0.5 & 0.5 & 0.8 & 0.0 & 0.0 & 0 . & 0.0 & 0.0 & 0.0 & & 99.5 & 98.7 & 97.2 & 97.2 & 96.7 & 96.2 & 96.0 & 3 & 638 \\
\hline 14 & 1.5 & 1.0 & 1.0 & 1.0 & 1.0 & 1.3 & 0.5 & 0.5 & 0.5 & 0.5 & 0.5 & 0.5 & 0.5 & & 98.2 & 96.7 & 96.7 & 96.2 & 95.7 & 95.5 & 14 & 5847 \\
\hline 15 & 1.0 & 0.5 & 0.5 & 0.5 & 0.5 & $0 . \varepsilon$ & 0.0 & 0.0 & 0. & 0 . & 0.0 & 0. & 0.0 & 0.5 & & 95.9 & 95.9 & 95.4 & 94.9 & |94.7 & 5 & 200 \\
\hline 16 & 2.8 & 2.3 & 2.3 & 2.3 & 2.3 & 2.6 & 2.8 & 2.8 & 2.8 & 2.8 & 2.8 & 2.8 & 2.8 & 3.4 & 2.9 & & 100.0 & 98.0 & 97.5 & 97.2 & 16 & 463 \\
\hline 17 & 2.8 & 2.3 & 2.3 & 2.3 & 2.3 & 2.6 & 2.8 & 2.8 & 2.8 & 2.8 & 2. & 2. & 2.8 & 3.4 & 3.4 & 0.0 & & 98.0 & 97.5 & 97.2 & 17 & F525297 \\
\hline 18 & 3.9 & 3.4 & 3.4 & 3.4 & 3.4 & 3.6 & 3.4 & 3.4 & 3.4 & 3.4 & 3.4 & 3.4 & 3.4 & 3.9 & 3.4 & 2.0 & 2.0 & & 99.5 & 99.2 & 18 & IQ423294 \\
\hline 15 & 4.4 & 3.9 & 3.9 & 3.9 & 3.9 & 4.2 & 3.9 & 3.9 & 3.9 & 3. & 3. & 3.9 & 3.9 & 4.4 & 4.0 & 2.6 & 2.6 & 0.5 & & \begin{tabular}{|l|}
98.7 \\
\end{tabular} & 19 & B235848 \\
\hline 20 & 4.4 & 3.9 & 3.9 & 3.9 & 3.9 & 4.2 & 3.9 & 3.9 & 3.9 & 3.9 & 3.9 & 3.9 & 3.9 & 4.4 & 4.0 & 2.6 & 2.6 & 0.5 & 1.0 & & 20 & QQ423292 \\
\hline & 1 & 2 & 3 & 4 & 5 & 0 & 7 & 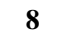 & J & 10 & 11 & 12 & 13 & 14 & 15 & 16 & 27 & 18 & 19 & 20 & & \\
\hline
\end{tabular}

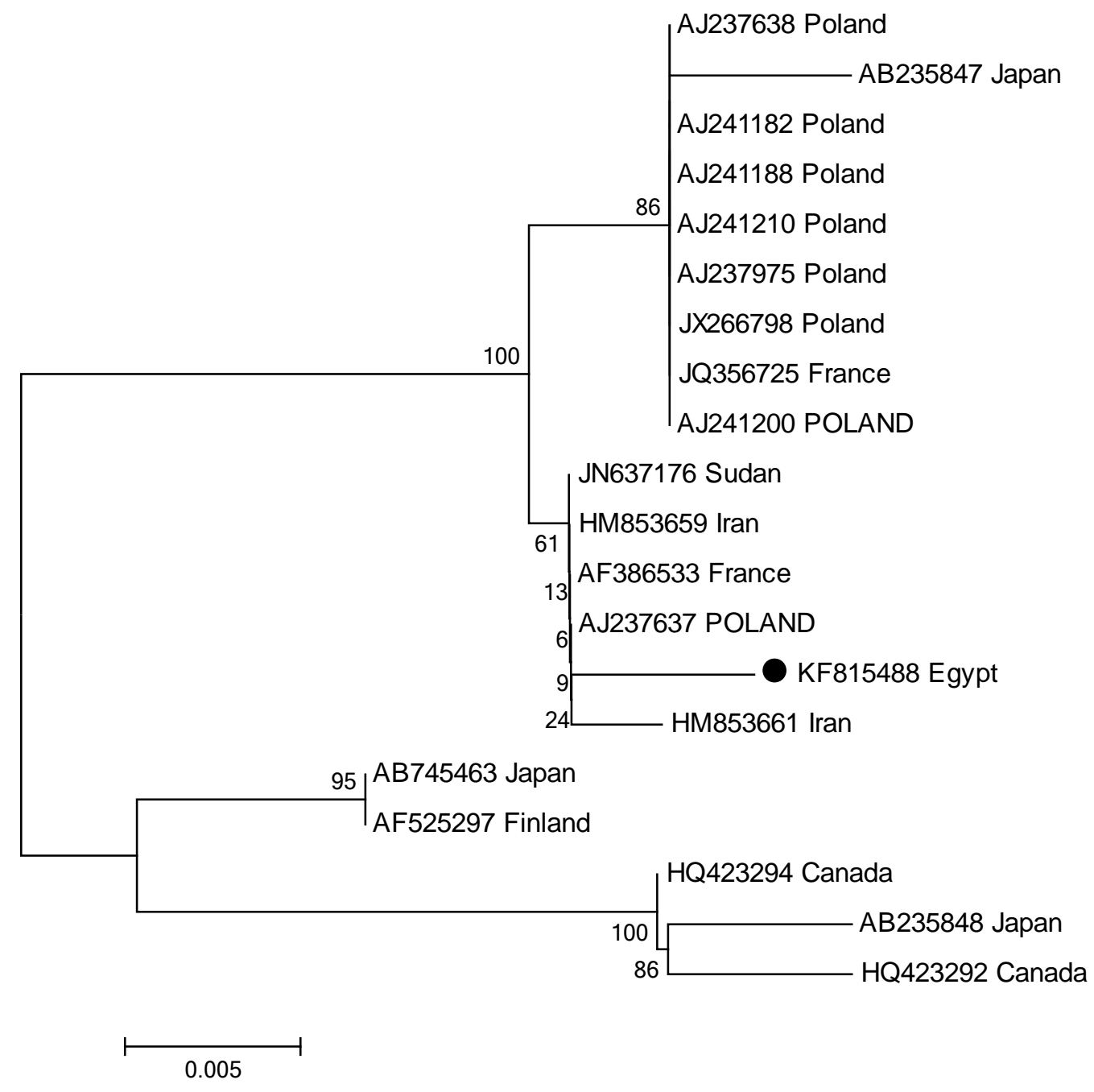

Figure 2. Phylogenetic tree sequences of Echinococcus granulosus (EG) from Egyptian camel and human and their relationship with reference sequences of other genotype G6 strain retrieved from GenBank. The tree analysis was obtained from partial sequence (276bp) from mitochondrial NADH dehydrogenase 1 gene. All isolates cluster with sequences belonging to the camel G6 genotype (Accession No. KF815488). A sequence aligned by Clustal W method and the tree was built by using MEGA5 software. Genetic distance is indicated below the tree 
Phylogenetic analysis showed a robust tree clustering all isolates with sequences belonging to the camel genotype (G6) variant with strong bootstrap values at relevant nodes. Phylogenetic tree shows the evolutionary relationship of the sequences in which the length of the horizontal line was proportional to the estimated genetic distance between the sequences. Such tree indicated that the evolutionary distance between groups is very short (Figure 2).

Protein sequence analysis indicated the presence of two mutations at the position of 92, where an Alanine (A) is changed to a Valine (V) and at the position of 129, where a Valine ( V) replaced by Proline (P) (Figure 3).

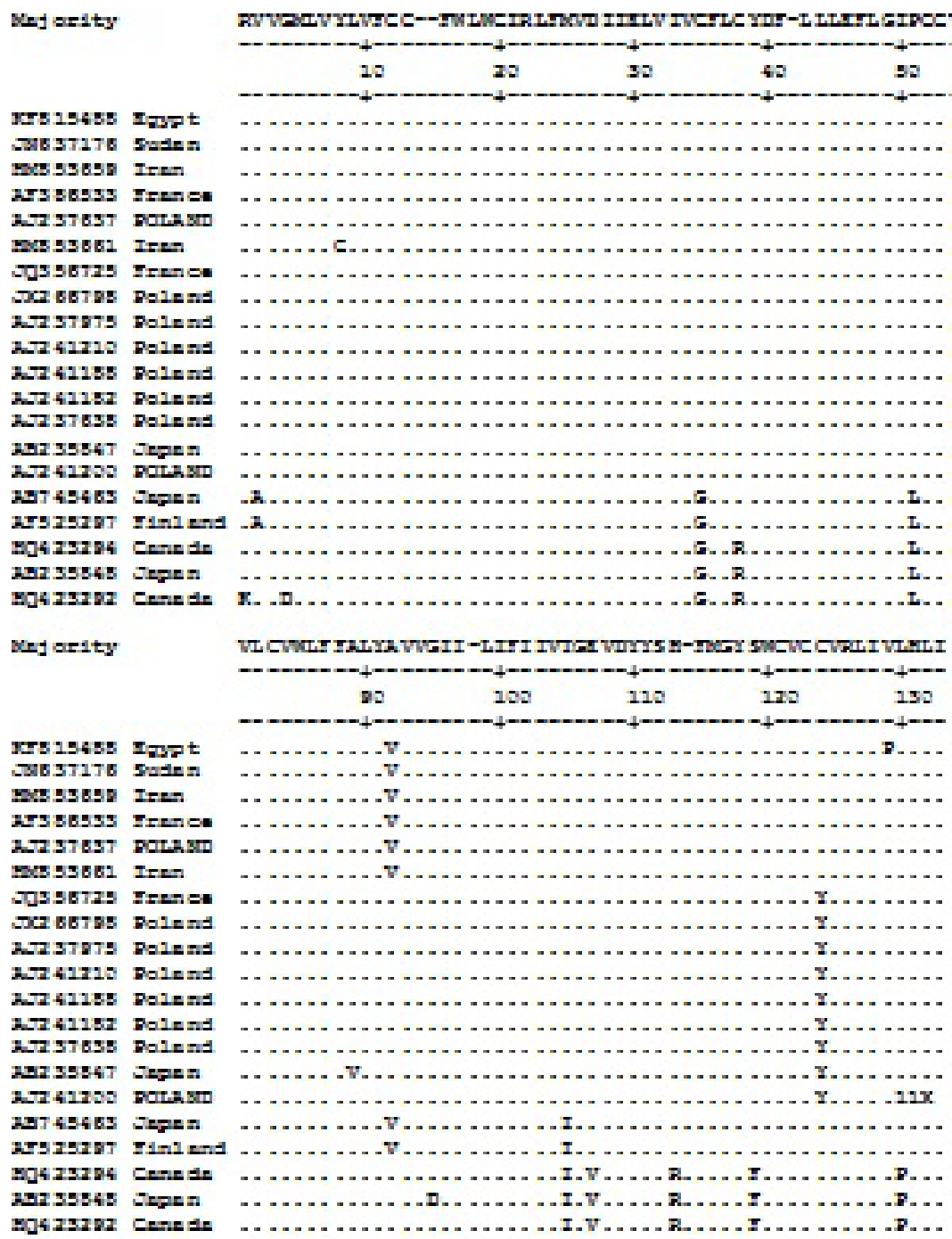

Figure 3. Protein sequence alignment of E. granulosus obtained from partial sequencing of NADH dehydrogenase 1 gene sequences aligned by MEGA5 with known strains sequences G6 in GenBank. Tow mutations in amino acids of KF815488 Egypt at positions 92 and 129

\section{Discussion}

Unilocular hydatidosis is a zoonotic parasitic disease representing a major public health problem in many countries around the world, including Egypt. Close relationships between dogs and humans appear to correlate with the high prevalence of the disease in endemic areas [18] and camel is an influential reservoir of the disease.

We selected the universal primers based on the highly conserved NADH dehydrogenase 1 gene [25] and our data indicated that the purified and partially sequenced PCR products generated 399 bp of NADH dehydrogenase 1 gene. The sequences were aligned by cluster grouping where the clusters aligned the most similar sequences firstly then progressively more distant groups of sequences until the global alignment was obtained. The NCBI-BLAST search found that our isolates are (100\%) homologues to the genotype E. canadensis (G6) and its accession number is KF 815488.

Analogous to our findings, recent studies indicated that the camel strain was reported to be the most predominant (100\%) among camels in Cairo, Egypt [22] and many African countries, such as Libya, Tunisia, Algeria, Sudan, and Mauritania (Table 2). In contrary, it has fewer existence in different countries worldwide (Table 3). E. canadensis G6 also infects sheep, goat, and cattle (Table 2 and Table 3). Taking together, these features provide strong evidence that camels play an important role for the maintenance of the Echinococcus life cycle in livestock intermediate hosts in Africa and Asia. On the contrary, camels appear to be suitable hosts for E. granulosus G1 infections (in Tunisia and Pakistan) and for G1, G3, G6, and G7 (in Iran) (Table 2 and Table 3). 
Table 2. Molecular epidemiology of cystic echinococcosis of animals reported in different African countries (2000 onwards)

\begin{tabular}{|c|c|c|c|c|c|}
\hline Location & Origin & No. isolates & Gene markers & Genotype frequency (\%) & Reference \\
\hline \multirow[t]{3}{*}{ Egypt } & Camels & 20 & nad1 & G6 (100\%) & The present study \\
\hline & Camels & 47 & 12S rRNA & G6 (100\%) & {$[22]$} \\
\hline & Pigs & 6 & 12S rRNA & G6 (100\%) & {$[22]$} \\
\hline Libya & Camels & 83 & cox1 and nad1 & G6 (100\%) & [27] \\
\hline \multirow[t]{2}{*}{ Algeria } & Camels & 6 & bg $1 / 3, \operatorname{cox} 1$ and nad 1 & G6 (100\%) & {$[27]$} \\
\hline & Camels & 10 & cox1, nad1, act2 and hbx2 & G6 (66.6\%); G1 (16.7\%); G2 (16.7\%) & [28] \\
\hline \multirow[t]{2}{*}{ Tunisia } & Camels & 3 & $\operatorname{cox} 1$ & G6 (100\%) & [29] \\
\hline & Camels & 13 & $\operatorname{cox} 1$ & G1 (100\%) & {$[30]$} \\
\hline \multirow[t]{11}{*}{ Sudan } & Camels & 35 & 12S rRNA, cox1 and nad1 & G6-G7 (100\%) & [31] \\
\hline & Camels & 61 & nad1 & G6 (100\%) & [23] \\
\hline & Camels & 207 & 12S rRNA, cox1 and nad1 & G6-G7 (100\%) & [1] \\
\hline & Camels & 30 & cox1 and nad1 & G6 (100\%) & {$[2]$} \\
\hline & Sheep & 3 & 12S rRNA, cox1 and nad1 & G6-G7 (100\%) & [31] \\
\hline & Sheep & 111 & 12S rRNA, cox1 and nad1 & G6-G7 (100\%) & {$[1]$} \\
\hline & Sheep & 28 & cox1 and nad1 & G6 (100\%) & {$[2]$} \\
\hline & Goats & 65 & 12S rRNA, cox1 and nad1 & G6-G7 (100\%) & {$[1]$} \\
\hline & Cattle & 8 & 12S rRNA, cox1 and nad1 & G6-G7 (75.0\%); G5 (25.0\%) & [31] \\
\hline & Cattle & 107 & 12S rRNA, cox1 and nad1 & G6-G7 (99.1\%); G5 (0.9\%) & [1] \\
\hline & Cattle & 62 & cox1 and nad1 & G6 (100\%) & {$[2]$} \\
\hline \multirow[t]{4}{*}{ Mauritania } & Camels & 3 & bg $1 / 3$, cox 1 and nad 1 & G6 (100\%) & [32] \\
\hline & Camels & 1 & 12S rRNA & G6-G7 (100\%) & [33] \\
\hline & Cattle & 20 & bg $1 / 3$, cox 1 and nad 1 & G6 (100\%) & {$[32]$} \\
\hline & Camels & 17 & cox1, nad1, act2 and hbx2 & G6 (100\%) & [33] \\
\hline \multirow[t]{3}{*}{ Kenya } & Sheep & 69 & nad1 & G6 (1.4\%) & [34] \\
\hline & Goat & 15 & nad1 & G6 (26.7\%) & {$[34]$} \\
\hline & Pigs & 4 & 12S rRNA, cox1 and nad1 & G1 (50.0\%); G6-G7 (25.0\%); G5 (25.0\%) & [31] \\
\hline
\end{tabular}

Act2: nuclear actin 2; bg 1/3: Echinococcus genus-specific genomic DNA; cox1: mitochondrial cytochrome c oxidase subunit 1; $h b x 2$ : nuclear homeobox 2; ITS1: ribosomal internal transcribed spacer 1; nad1: mitochondrial NADH dehidrogenase subunit 1; 12S rRNA: mitochondrial 12S small subunit ribosomal RNA.

Table 3. Molecular epidemiology of cystic echinococcosis of animals reported in different countries (2000 onwards).

\begin{tabular}{|c|c|c|c|c|c|}
\hline Country & Origin & No. isolates & Gene markers & Genotype frequency (\%) & Reference \\
\hline \multicolumn{6}{|l|}{ Asia } \\
\hline \multirow[t]{9}{*}{ Iran } & Camels & 32 & ITS1 DNA & G1 (25.0\%); G6 (75.0\%) & [35] \\
\hline & Camels & 2 & ITS1 DNA & Likely G6-G7 (100\%) & {$[36]$} \\
\hline & Camels & 19 & cox1 and nad1 & G1-G3 (68.4\%); G6-G10 (31.6\%) & {$[37]$} \\
\hline & Camels & 18 & ITS1 DNA & G1 (66.7\%); G6 (33.3\%); & {$[37]$} \\
\hline & Camels & 26 & cox1, nad1, ITS1 DNA & G1 (34.6\%); G6 (65.4\%) & [38] \\
\hline & cattle & 14 & cox1, nad1, ITS1 DNA & G1 (64.3\%); G6 (35.7\%) & [38] \\
\hline & Camels & 9 & cox1 and nad1 & G1 (44.4\%); G3 (22.2\%); G7 (33.3\%) & [39] \\
\hline & camels & 43 & cox1, nad1, atp6 and 12S rRNA & G1 (88.4\%); G6 (11.6\%) & [40]) \\
\hline & Camels & 19 & cox1 and nad1 & G1 (26.3\%); G3 (42.1\%); G6 (31.6\%) & {$[41]$} \\
\hline Pakistan & Camels & 5 & $\operatorname{cox} 1$ & G1 (100\%) & {$[42]$} \\
\hline \multicolumn{6}{|l|}{ America } \\
\hline Mexico & Pigs & 7 & cox1, ITS1 DNA & G6-G7 (100\%) & {$[43]$} \\
\hline Argentina & goats & 3 & $\operatorname{cox} 1, m d h$ & G6 (100\%) & {$[44]$} \\
\hline \multicolumn{6}{|l|}{ Europe } \\
\hline \multirow[t]{2}{*}{ Lithuania } & Cattle & 1 & $\operatorname{cox} 1$ & G6-G7 (100\%) & [45] \\
\hline & Pigs & 7 & $\operatorname{cox} 1$ & G6-G7 (100\%) & {$[46]$} \\
\hline
\end{tabular}

Atp6: mitochondrial ATP synthase subunit 6; cox1: mitochondrial cytochrome c oxidase subunit 1; ITS1: ribosomal internal transcribed spacer 1; mdh cytosolic malate dehydrogenase; nad1: mitochondrial NADH dehidrogenase subunit 1; 12S rRNA: mitochondrial 12S small subunit ribosomal RNA. 
Molecular epidemiological data in African pigs are recently only available from Egypt and Kenya. In Egypt, all swine isolates were identified as E. canadensis G6) [22], whereas Kenyan pigs were demonstrated to be predominantly infected with E. granulosus s.s. (genotype frequency: 50\%), E. canadensis G6-G7, and E. ortleppi being responsible for $25 \%$ of the total infections each [31].

The exclusive finding of the G6 variant in all camel and human isolates in Qalyubia Governorate, Egypt indicates the presence of a predominant transmission cycle in which the camel strain exist. Our findings confirms a previous study done using RAPD-PCR for characterization of human and animal hydatid cysts, it has been shown that human and camel isolates were the most related pair and camels are important hosts for the transmission of human hydatidosis (Azab et al. 2004) [47]. Similarly, performing the cycle sequencing and nucleotide sequence analysis identified the G6 genotype in 30 (96.8\%) out of 31 human isolates in Cairo, Egypt) [22].

Although the camel strain G6 is traditionally considered as less infective to humans $[48,49]$ recent molecular findings [29], [23] and [22] as well as ours suggest that the prevalence of infection of this genotype may be higher than previously thought. Among the ten genotypes of $E$. granulosus (EG) recognized worldwide, only 5 strains were known to infect humans including G1, G2, G5, G6, and G7 strains (Table 4). The most frequent strain associated with human CE appears to be the sheep strain (G1) and the highest rates of infection are recorded in communities involved in extensive sheep farming [50].

Table 4. Molecular epidemiology of cystic echinococcosis of humans in different countries (2000 onwards)

\begin{tabular}{|c|c|c|c|c|}
\hline Country & No. isolates & Gene markers & Genotype frequency (\%) & Reference \\
\hline \multirow[t]{2}{*}{ Egypt } & 5 & nad1 & G6 (100\%) & The present study \\
\hline & 31 & nad1 & G1 (3.2\%); G6 (96.8\%) & [22] \\
\hline Tunisia & 11 & $\operatorname{cox} 1$ & G1 (100) & [29] \\
\hline Sudan & 3 & nad1 & G6 (100\%) & [23] \\
\hline Kenya & 59 & cox1, nad1 & G1 (83\%); G6 (17\%) & [49] \\
\hline South Africa & 32 & nad1, 125 rRNA & G1-G3 (81\%); G6/G7 (16\%); G5 (3\%). & [51] \\
\hline \multirow[t]{2}{*}{ Iran } & 31 & cox1, nad1, ITS1 DNA & G1 (80.6\%); G6 (19.4\%) & [39] \\
\hline & 4 & ITS1 DNA & G1-G3 (100\%) & [52] \\
\hline Poland & 30 & nad1 & G7 (100\%) & [53] \\
\hline Peru & 20 & $\operatorname{cox} 1$ & G1 (95\%); G6 (5\%) & [48] \\
\hline
\end{tabular}

cox1: mitochondrial cytochrome c oxidase subunit 1; ITS1: ribosomal internal transcribed spacer 1; nad1: mitochondrial NADH dehydrogenase subunit 1; 12S rRNA: mitochondrial 12S small subunit ribosomal RNA.

Sequencing of our samples revealed mutations in three nucleotides generating a change at the level of 275 nucleotide, where a $\mathrm{T}$ replaced a C Similar mutation had been recorded for strains isolated from Sudan, Iran, France, and Poland (Figure 1). In addition, our isolate revealed two other mutations at the levels of 385 and 386 nucleotides, where CC substituted GT. These mutations did not express in the previously mentioned international isolates. In contrary to our finding, the solely recorded Egyptian G6 strain isolated by [22] pointed out to the presence of a substitution of one nucleotide at the site number 207, in which a C is substituted by a T, after examining another mitochondrial gene, 12S rRNA.

Our isolate showed $99.5 \%$ identity with similar isolates from Sudan, Iran, France, and Poland. On the other hand, our isolate expressed $96.6 \%$ identity with that of the Canadian isolate (Table 1). On comparing the obtained nucleotide sequences (of mitochondrial 12S rRNA gene) of the only isolated Egyptian strain by [22] (Genbank ID: GQ476732-GQ476735) with that of the Argentinean G6 reference strain (GenBank accession no. AB208063), $100 \%$ identity was found.

Phylogenetic analysis showed that our isolates clustered with E. canadensis (G6) and revealed that KF815488 Egypt put in the same category with JN637176 Sudan, HM853659 Iran, AF386533 France and AJ237637 Poland. Phylogenetic tree indicated that the evolutionary distance between groups is very short, suggesting that the genetic divergence is recent.

Nucleotide mutations are translated to mutations in the protein sequence as our data refer to the presence of a $\mathrm{V}$ instead of an $\mathrm{A}$, at the level of 92, and a $\mathrm{P}$ instead of a V, at the position 129. Similar V replacement at the site of number 92 had been recorded in Sudan, France, Poland, and Iran (Figure 3).

Our findings of nucleotide and protein mutations explain the higher human infectivity (100\%) of G6 as all collected hydatid cysts of camels and humans were fertile. This is of great epidemiological importance as the fertile hydatid cysts are responsible for progression of the life cycle and acting as a reservoir for human [54] The occurrence of mutations explains why the camel strain (G6 genotype) appears to affect humans in certain geographical areas but not others. Similar finding had been recorded [55]

The extensive intraspecific variation in E. granulosus is associated with change in the life cycle pattern, host specificity, geographical distribution, transmission dynamics, infectivity to human, antigenicity, and sensitivity to chemotherapy $[21,56]$.

\section{Conclusion}

For the first time in Qalyubia, Egypt, we successfully investigated the molecular characterization of Echinococcus genotype and highlighted the polymorphism of nucleotide and protein mutations of E. canadensis (G6) in camels and human patients which could explain the increased infectivity to humans. Our record of a single genotype, G6, suggests that similar mechanisms are responsible for its persistence in the endemic areas. Such epidemiological data could guide the application of efficient control strategies of CE in Egypt. 


\section{Further Studies}

Our study may provide a foundation for future epidemiological studies on the transmission dynamics of the parasite as well as studying the function of malformed proteins and their efficacy on the infectivity of CE in different intermediate hosts as well as their effect on the sensitivity to chemotherapeutic agents.

\section{Acknowledgment}

The authors are very grateful to Dr. Ehab M. AbdelFattah, Senior consultant of General and Oncology Surgery (Benha Insurance hospital, Qalyubia, Egypt) for his help in supplied human hydatid fluids.

\section{References}

[1] Omer, R.A., Dinkel, A., Romig, T., Mackenstedt, U., Elnahas, A.A., Aradaib, I.E., Ahmed, M.E., Elmalik, K.H., Adam, A. (2010). A molecular survey of cystic echinococcosis in Sudan. Veterinary Parasitology 169, 340-346.

[2] Ibrahim, K., Thomas, R., Peter, K. and Omer, R.A. (2011). A molecular survey on cystic echinococcosis in Sinnar area,Blue Nile state (Sudan). Chinese Medical Journal (Engl.) 124, 28292833.

[3] Salih, M., Degefu, H. and Yohannes, M. (2011). Infection rates, cyst fertility and larval viability of hydatid dsease in camels (Camelus dromedarius) from Borena, Kereyu and Harar aeas of Ethiopia. Global Veterinaria 7, 518-522.

[4] Sadjjadi, M.S. (2006). Present situation of echinococcosis in the Middle East and Arabic North Africa. Parasitology international 55 (S3), 197-202.

[5] Njoroge, E.M., Mbithi, P.M., Gathuma, J.M., Wachira, T.M., Gathura, P.B., Magambo, J.K. and Zeyhle, E. (2002). A study of cystic echinococcosis in slaughter animals in three selected areas of northern Turkana, Kenya. Veterinary parasitology 104, 85-91.

[6] Ahmadi, N.A. (2005). Hydatidosis in camels (Camelus dromedarius) and their potential role in the epidemiology of Echinococcus granulosus in Iran. Journal of Helminthology 79, 119-125.

[7] Torgerson, P.R., Oguljahan, B., Muminov, A.E., Karaeva, R.R., Kuttubaev, O.T., Aminjanov, M. and Shaikenov, B. (2006). Present situation of cystic echinococcosis in Central Asia. Parasitology International 55 (Suppl), S207-S212.

[8] Ibrahim, M.M. (2010). Study of cystic echinococcosis in slaughtered animals in Al Baha region, Saudi Arabia: interaction between some biotic and abiotic factors. Acta Tropica 113, 26-33.

[9] Epsinosa, S., Salas, A.M., Vargas, A. Freire, V., Diaz, E., Sánchez, G. and Venegas, J. (2014). Detection of G3 genotype of Echinococcus granulosus from hydatid cysts of Chilean cattle using COX1 and ND1 mitochondrial markers. Parasitology Research 113 (1), 139-147.

[10] Jenkins, D.J. (2006). Echinococcus granulosus in Australia, widespread and doing well! Parasitology International 55 (Suppl), S203-S206.

[11] Torgerson, P.R. (2003). Economic effects of echinococcosis. Acta Tropica 85 (2), 113-118(6)

[12] Naseri- Moghddam, S., Abrishami, A., Taefi, A. and Malekzadeh, R. (2011). Percutaneous needle aspiration injection, and reaspiration with or without benzimidazole coverage for uncomplicated hepatic hydatid cysts. Cochrane Database. Syst. Rev., pp: CD003623.

[13] Jenkins, D.J., Romig, T. and Thompson, R.C. (2005). Emergence/re-emergence of Echinococcus spp. - a global update. International Journal for Parasitology 35, 1205-1219.

[14] Budke, C.M., Deplazes, P. and Torgerson, P.R. (2006). Global socioeconomic impact of cystic echinococcosis. Emerging Infectious Diseases 12, 296-303.

[15] Sako, Y., Tappe, D., Fukuda, K., Kobayashi, Y. and Ito A (2011). Immunochromatographic test with recombinant Em18 antigen for the follow- up study of alveolar Echinococcosis. Clinical and Vaccine Immunology 18 (8), 1302-1305.

[16] Sarkari, B., Sadjjadi, S.M., Abidi, H. and Rafati, A. (2007). Application of western blotting using native antigen $\mathrm{B}$ for serodiagnosis of human cystic echinococcosis. Iranian Journal of Parasitology 2(3), 7-12.

[17] Sako,Y., Nakao, M., Nakaya, K., Yamasaki, H., Gottstein, B. and Ito, A. (2002). Alveolar echinococcosis: characterization of diagnostic antigen Em18 and serological evaluation of recombinant Em18. Journal of Clinical Microbiology 40, 27602765.

[18] Moro, P.L. and Schantz, P.M. (2009). Echinococcosis: a review. International Journal of Infectious Diseases 13, 125-133.

[19] Cardona, G.A. and Carmena, D. (2013). A review of the global prevalence, molecular epidemiology and economics of cystic echinococcosis in production animals. Veterinary parasitology 192, 10-32.

[20] Huttner, M., Nakao, M., Wassermann, T., Siefert, L., Boomker, J.D., Dinkel, A., Sako, Y., Mackenstedt, U., Romig, T. and Ito, A. (2008). Genetic characterization and phylogenetic position of Echinococcus felidis (Cestoda:Taeniidae) from the African lion. International Journal for Parasitology 38, 861-868.

[21] Thompson, R.C., McManus, D.P., 2002. Towards a taxonomic revision of the genus Echinococcus. Trends in Parasitology 18 (10), $452-457$.

[22] Abdel Aaty, H.E., Abdel-Hameed, D.M., Alam-Eldin, Y.H. and El- Shenawy, S.F. Aminou H.A., Makled S.S., Darweesh,S.K. (2012). Molecular genotyping of E. granulosus in animal and human isolates from Egypt. Acta Tropica 121(2), 125-128.

[23] Osman, A.M., Aradaib, I.E., Ashmaig, A.K. and Gameel, A.A. (2009). Detection and differentiation of Echinococcus granulosuscomplex using a simple PCR -based assay. International Journal of Tropical Medicine 4 (1), 21-26.

[24] Tamura, K., Peterson, D., Peterson, N., Stecher, G., Nei, M. and Kumar, S. (2011). MEGA5: Molecular Evolutionary Genetics Analysis using Maximum Likelihood, Evolutionary Distance, and Maximum Parsimony Methods. Molecular Biology and Evolution 28, 2731-2739

[25] Bowles. J. and McManus, D.P. (1993). NADH dehydrogenase 1 gene sequences compared for species and strains of the genus Echinococcus. International Journal for Parasitology 23, 969-972.

[26] Abushhewa, M.H., Abushhiwa, M.H., Nolan, M.J., Jex, A.R., Campbell, B.E., Jabbar, A. and Gasser, R.B. (2010). Genetic classification of Echinococcus granulosus cysts from humans, cattle and camels in Libya using mutation scanning-based analysis of mitochondrial loci. Molecular and Cellular Probes 24, 346-351.

[27] Bardonnet, K., Benchikh-Elfegoun, M.C., Bart, J.M., Harraga, S., Hannache, N., Haddad, S., Dumon, H., Vuitton, D.A. and Piarroux, R. (2003). Cystic echinococcosis in Algeria: cattle act as reservoirs of a sheep strain and may contribute to human contamination. Veterinary parasitology 116, 35-44.

[28] Maillard, S., Benchikh-Elfegoun, M.C., Knapp, J., Bart, J.M., Koskei, P., Gottstein, B. and Piarroux, R. (2007). Taxonomic position and geographical distribution of the common sheep G1 and camel G6 strains of Echinococcus granulosus in three African countries. Parasitology Research 100, 495-503.

[29] M’Rad, S., Filisetti, D., Oudni, M., Mekki, M., Belguith, M., Nouri, A., Sayadi, T., Lahmar, S., Candolfi, E., Azaiez, R, Mezhoud, H. and Babba, H. (2005). Molecular evidence of ovine (G1) and camel (G6) strains of Echinococcus granulosus in Tunisia and putative role of cattle in human contamination. Veterinary parasitology 129, 267-272.

[30] Lahmar, S., Debbek, H., Zhang, L.H., McManus, D.P., Souissi, A. Chelly, S. and Torgerson, P.R. (2004). Transmission dynamics of the Echinococcus granulosus sheep-dog strain (G1 genotype) in camels in Tunisia. Veterinary parasitology 121, 151-156.

[31] Dinkel, A., Njoroge, E.M., Zimmermann, A., Walz, M., Zeyhle, E., Elmahdi, I.E., Mackenstedt, U. and Romig, T. (2004). A PCR system for detection of species and genotypes of the Echinococcus granulosus-complex, with reference to the epidemiological situation in eastern Africa. International Journal for Parasitology 34, 645-653.

[32] Bardonnet, K., Piarroux, R., Dia, L., Schneegans, F., Beurdeley, A., Godot, V. and Vuitton, D.A. (2002). Combined ecoepidemiological and molecular biology approaches to assess Echinococcus granulosus transmission to humans in Mauritania: occurrence of the 'camel' strain and human cystic echinococcosis. 
[33] Farjallah, S., Busi, M., Mahjoub, M.O., Slimane, B.B., Said, K. and D'Amelio, S. (2007). Molecular characterization of Echinococcus granulosus in Tunisia and Mauritania by mitochondrial rrnS gene sequencing. Parassitologia 49 (4), 239246.

[34] Addy, F., Alakonya, A., Wamae, N., Magambo, J., Mbae, C., Mulinge, E., Zeyhle, E., Wassermann, M., Kern, P. and Romig, T. (2012). Prevalence and diversity of cystic echinococcosis in livestock in Maasailand, Kenya. Parasitology Research 111(6), 2289-94

[35] Harandi, M.F., Hobbs, R.P., Adams, P.J., Mobedi, I., MorganRyan, U.M. and Thompson, R.C. (2002). Molecular and morphological characterization of Echinococcus granulosus of human and animal origin in Iran. Parasitology 125, 367-373.

[36] Ahmadi, N. and Dalimi A (2006). Characterization of Echinococcus granulosus isolates from human, sheep and camel in Iran. Infection Genetics and Evolution 6, 85-90.

[37] Sharbatkhori, M., Mirhendi, H., Jex, A.R., Pangasa, A., Campbell, B.E., Kia, E.B., Eshraghian, M.R., Harandi, M.F. and Gasser, R.B. (2009). Genetic categorization of Echinococcus granulosus from humans and herbivorous hosts in Iran using an integrated mutation scanning-phylogenetic approach. Electrophoresis 30, 2648-2655.

[38] Sharbatkhori, M., Mirhendi, H., Harandi, M.F., Rezaeian, M., Mohebali, M., Eshraghian, M., Rahimi, H. and Kia, E.B. (2010). Echinococcus granulosus genotypes in livestock of Iran indicating high frequency of G1 genotype in camels. Experimental Parasitology 124, 373-379.

[39] Shahnazi, M., Hejazi, H., Salehi, M., Andalib, A.R. (2011). Molecular characterization of human and animal Echinococcus granulosus isolates in Isfahan, Iran. Acta Tropica 117, 47-50.

[40] Hajialilo, E., Harandi, M.F., Sharbatkhori, M., Mirhendi, H. and Rostami, S. (2012). Genetic characterization of Echinococcus granulosus in camels, cattle and sheep from the south-east of Iran indicates the presence of the G3 genotype. Journal of Helminthology 86, 263-270.

[41] Rostami Nejad, M., Taghipour, N., Nochi, Z., Nazemalhosseini Mojarad, E., Mohebbi, S.R., Fasihi Harandi, M. and Zali, M.R. (2012). Molecular identification of animal isolates of Echinococcus granulosus from Iran using four mitochondrial genes. Journal of Helminthology 86(4), 485-492.

[42] Simsek, S., Balkaya, I., Ciftci, A.T. and Utuk, A.E. (2011). Molecular discrimination of sheep and cattle isolates of Echinococcus granulosus by SSCP and conventional PCR in Turkey. Veterinary parasitology 178, 367-369.

[43] Latif, A.A., Tanveer, A., Maqbool, A., Siddiqi, N., Kyaw-Tanner, M., Traub, R.J. (2010). Morphological and molecular characterisation of Echinococcus granulosus in livestock and humans in Punjab, Pakistan. Veterinary parasitology 70, 44-49.

[44] Cruz-Reyes, A., Constantine, C.C., Boxell, A.C., Hobbs, R.P. and Thompson, R.C. (2007). Echinococcus granulosus from Mexican pigs is the same strain as that in Polish pigs. Journal of Helminthology 81, 287-292.
[45] Kamenetzky, L., Gutierrez, A.M., Canova, S.G., Haag, K.L., Guarnera, E.A., Parra, A., Garcia, G.E. and Rosenzvit, M.C. (2002). Several strains of Echinococcus granulosus infect livestock and humans in Argentina. Infection, Genetics and Evolution 2, 129-136.

[46] Bruzinskaite, R., Sarkunas, M., Torgerson, P.R., Mathis, A. and Deplazes, P. (2009). Echinococcosis in pigs and intestinal infection with Echinococcus spp. in dogs in southwestern Lithuania. Veterinary parasitology 160, 237-241

[47] Azab, M.E., Bishara, S.A., Helmy, H., Oteifa, N.M., El-Hoseiny, L.M., Ramzy, R.M. and Ahmed, M.A. (2004). Molecular characterization of Egyptian human and animal Echinococcus granulosus isolates by RAPD-PCR technique. Journal of the Egyptian Society of Parasitology 34(1), 83-96.

[48] Santivañez, S.J., Gutierrez, A.M., Rosenzvit, M.C., Muzulin, P.M., Rodriguez, M.L., Vasquez, J.C., Rodriguez, S., Gonzalez, A.E., Gilman, R.H., Garcia, H.H. and The Cysticercosis Working Group in Peru (2008). Human hydatid disease in Peru is basically restricted to Echinococcus granulosus Genotype G1. American Journal of Tropical Medicine and Hygiene, 89-92.

[49] Casulli, A., Zeyhle, E., Brunetti, E., Pozio, E., Meroni, V., Genco, F. and Filice, C. (2010). Molecular evidence of the camel strain (G6 genotype) of Echinococcus granulosus in humans from Turkana, Kenya. Transactions of the Royal Society of Tropical Medicine and Hygiene 104 (1), 29-32.

[50] Grosso, G., Gruttadauria, S., Biondi, A., Marventano, S. and Mistretta, A. (2012). Worldwide epidemiology of liver hydatidosis including the Mediterranean area. World Journal of Gastroenterology 18(13), 1425-1437.

[51] Mogoye, B.K., Menezes, C.N., Wong, M.L., Stacey, S., von Delft, D., Wahlers, K., Wassermann, M., Romig, T., Kern, P., Grobusch, M.P. and Frean, J. (2013). First insights into species and genotypes of Echinococcus in South Africa. Veterinary Parasitology, in press.

[52] Dousti, M., Abdi, J., Bakhtiyari, S., Mohebali, M., Mirhendi,S.H. and Rokni,M.B. (2013). Genotyping of Hydatid Cyst Isolated from Human and Domestic Animals in Ilam Province, Western Iran Using PCR-RFLP. Iranian Journal of Parasitology 8 (1), 4752.

[53] Dybicz, M., Gierczak, A., Dąbrowska, J., Rdzanek, L. and Michałowicz, B. (2013). Molecular diagnosis of cystic echinococcosis in humans from central Poland. Parasitology International 62, 364-367.

[54] Dyab, K.A., Hassanein, R., Hussein, A.A., Metwally, S.E. and Gaad, H.M. (2005). Hydatidosis among man and animals in Assiut and Aswan Governorates. Journal of Egyptian society of parasitology 35, 157-166.

[55] Rosenzvit, M.C., Zhang, L.H., Kamenetzky, L., Canova, S.G., Guarnera, E.A. and McManus, D.P. (1999). Genetic variation and epidemiology of Echinococcus granulosus in Argentina. Parasitology 118, 523-530

[56] Romig, T. (2003). Epidemiology of echinococcosis. Langenbeck's Archives of Surgery 388 (4), 209-217. 